\title{
MOVPE growth of GaP on Si with As initial coverage
}

\author{
A. Navarro ， E. García-Tabarés , B. Galiana , P. Caño I. Rey-Stolle , C. Ballesteros
}

\begin{abstract}
A B S T R A C T
The growth of a GaP $50 \mathrm{~nm}$ layer on Si by metalorganic vapor phase epitaxy is studied using $\mathrm{AsH}_{3}$ and $\mathrm{PH}_{3}$ preexposure at low $\left(550^{\circ} \mathrm{C}\right)$ and high $\left(800^{\circ} \mathrm{C}\right)$ growth temperatures. The samples are characterized by transmission electron microscopy. The results obtained reveal that the use of As as a first coverage layer on top of misorientated Si-substrates favors the formation of a defect-free GaP epitaxial layer, for a wide range of $\mathrm{AsH}_{3}$ pre-exposure times using high growth temperature $\left(800^{\circ} \mathrm{C}\right)$, even though relatively low $\mathrm{Si}$ substrate annealing temperatures are used $\left(850^{\circ} \mathrm{C}\right)$ and no homoepitaxial $\mathrm{Si}$ layer was first grown. The procedure presented in this work reduces the thermal budget and complexity compared to most previous GaP/Si routines.
\end{abstract}

\section{Introduction}

The integration of III-V semiconductors on silicon has been suggested as a promising technology to reduce the cost of optoelectronics, solar cells and high speed electronics, due to the optical and electronic functionality of III-V semiconductors combined with the mature and low cost silicon-based microelectronic technology [1,2]. For all the applications mentioned above, the suitable III-V materials exhibit a large lattice mismatch to $\mathrm{Si}$ which hinders their integration. For example, for multijunction solar cells the maximum theoretical efficiency for a III-V semiconductor on Si Dual-Junction Solar Cell (DJSC) is $40 \%$ for a $\mathrm{GaAs}_{0.8} \mathrm{P}_{0.2} / \mathrm{Si}$ solar cell [3] which presents a $3.24 \%$ lattice mismatch between both materials. A common approach is the formation of a virtual III-V substrate, by growing a GaP nucleation layer on the Si-substrate, acting as a template for the growth of the complete III-V semiconductor structure since this heteroepitaxial growth $(\mathrm{GaP} / \mathrm{Si})$ has the minimum lattice mismatch for a III-V on $\mathrm{Si}$, i.e $0.36 \%$. However, the system $(\mathrm{GaP} / \mathrm{Si})$ presents certain challenges that degrade the quality of the layers: i) the epitaxial strain or three dimensional growth, that leads to the formation of defects at the GaP/ $\mathrm{Si}$ heterointerface or/and in the epitaxial layer [4-6]; ii) the growth of a polar III-V semiconductor (i.e. GaP) on a nonpolar substrate (i.e. Si) induces the formation of antiphase domains (APD) [5-9], which, if they are not annihilated or avoided will be detrimental for devices; and iii) the unwanted cross doping through the interface [9]. Recent and very promising studies opened the possibility of modifying the surface of a Si-substrate by As-coverage (close to $1 \mathrm{ML}$ ) and thermal treatments previous to the GaP deposit [10].

The development of well-controlled growth procedures to achieve defect free $\mathrm{GaP}$ layers on $\mathrm{Si}$ is thus critical for the performance of the final devices and for industrial development.

The main requirements to achieve a successful growth of $\mathrm{GaP}$ on $\mathrm{Si}$ according to the literature are: i) the achievement of a clean Si surface free of any contaminants, especially $\mathrm{C}$ and $\mathrm{O}$, since they can behave as nucleation centers for defects at the $\mathrm{GaP} / \mathrm{Si}$ interface and ii) the formation of a single domain Si surface before III-V growth to avoid the formation of antiphase domains (APDs).

To achieve a clean Si surface most authors suggested a thermal treatment at high temperature (above $850^{\circ} \mathrm{C}$ ) under hydrogen not only to obtain an oxide and carbon-free surface but also to achieve doublestep reconstruction on the Si wafer [5,6,9-14]. Some other authors also use homoepitaxial $\mathrm{Si}$ growth to bury any residual contaminant $[4,7,8,15,16]$. This last approach requires As-clean MOVPE reactors, and consequently growth interruptions and/or multi-reactor processes.

For the formation of a double-stepped Si surface to avoid APDs, the most common strategy is the use of misoriented Si wafers to enhance the formation of double steps at high temperature [5]; once this is achieved, the Si surface is pre-exposed to either group III or V elements in order to favor the formation of a given reconstruction of a Ga, As or $P$ monolayer (ML). Regarding this pre-exposure or pre-nucleation step there is a wide range of approximations reported; how different preexposures affect subsequent growths has also been studied [17]. In MOVPE growth, most routines are based on group-V pre-exposure since the adsorption of group $\mathrm{V}$ elements with high vapor pressure on the surface is a self-limited phenomenon, contrary to exposure to group III atoms that tend to form clusters. The use of a P ML, either at high temperature [12-14] or low temperature $[7,8,15]$ has been the most commonly reported strategy. In those cases in which low temperature 
Table 1

Description of the pre-exposure routine for each sample.

\begin{tabular}{lllll}
\hline \multirow{2}{*}{ Sample } & \multicolumn{3}{l}{ Pre-exposure } & \\
\cline { 2 - 5 } & Group V & Time (s) & Temp $\left({ }^{\circ} \mathrm{C}\right)$ & Flow (moles/s) \\
\hline $\mathrm{As}-30 \mathrm{~s}-800 \mathrm{C}$ & $\mathrm{AsH}_{3}$ & 30 & 800 & $7.43 \cdot 10^{-6}$ \\
$\mathrm{As}-360 \mathrm{~s}-800 \mathrm{C}$ & $\mathrm{AsH}_{3}$ & 360 & 800 & $7.43 \cdot 10^{-6}$ \\
$\mathrm{P}-30 \mathrm{~s}-800 \mathrm{C}$ & $\mathrm{PH}_{3}$ & 30 & 800 & $3.71 \cdot 10^{-4}$ \\
$\mathrm{P}-30 \mathrm{~s}-550 \mathrm{C}$ & $\mathrm{PH}_{3}$ & 30 & 550 & $3.35 \cdot 10^{-4}$ \\
As-30 s-550C & $\mathrm{AsH}$ & 30 & 550 & $7.43 \cdot 10^{-6}$ \\
\hline
\end{tabular}

$\mathrm{GaP}$ growth is required, tertiarybutylphosphine (TBP) is needed for an efficient pyrolysis of the P precursor. In comparison, only few works are based on As ML $[6,10,11,18]$. Just recently, the use of $\mathrm{AsH}_{3}$ at high temperatures has been reported as giving promising results with $\mathrm{Si}$ substrate annealing below $850^{\circ} \mathrm{C}$ [18]. In that work, the Si surface was exposed to $\mathrm{AsH}_{3}$ at temperatures between 690 and $740{ }^{\circ} \mathrm{C}$.

All these factors mentioned before increase the growth complexity, due to the time consumption, the thermal budget and the specific equipment requirements, making difficult the integration of $\mathrm{GaP}$ on $\mathrm{Si}$ technology with the standards required for the industry. Additionally, the number of parameters involved in the achievement of a defect free GaP layer is quite large (growth mode -continuous or pulsed-, growth temperature, pre-nucleation, etc) making the reported results noneasily transferrable to industry or even to other research reactors.

Accordingly, the main goal of this work is to set the basis for developing a GaP-on-Si growth procedure with: i) a lower thermal budget by reducing the Si annealing temperature; ii) one step growth (no reactor changes or growth interruption); and iii) wide range of growth parameters.

In order to determine the limits of the growth parameters that allow a defect-free $\mathrm{GaP} / \mathrm{Si}$ growth and to have a deeper understanding of the nucleation process, the $\mathrm{AsH}_{3}$ pre-exposure time and growth temperature have been varied. $\mathrm{PH}_{3}$ pre-exposure has been also tested at low $\left(550^{\circ} \mathrm{C}\right)$ and high temperature $\left(800^{\circ} \mathrm{C}\right)$, for comparison.

\section{Experimental}

Epilayers of GaP were prepared using a horizontal AIX200/4 MOVPE reactor on $\mathrm{Si}(100)$ substrates with a $2^{\circ}$ miscut toward the nearest (111) plane. Wafers were deoxidized using an $\mathrm{HF}$ dip and preheated at $800{ }^{\circ} \mathrm{C}$ in a $\mathrm{H}_{2}$ flow for $30 \mathrm{~min}$ in order to remove any residual traces of silicon oxide and to promote the reconstruction of the surface. Before the GaP growth initiation, the substrates were exposed to two types of preflows $\left(\mathrm{AsH}_{3}\right.$ or $\left.\mathrm{PH}_{3}\right)$ at low temperature $\left(550{ }^{\circ} \mathrm{C}\right)$ or high temperature $\left(800^{\circ} \mathrm{C}\right)$. The $\mathrm{GaP}$ layer was grown in continuous mode by supplying TMGa and $\mathrm{PH}_{3}$ as source materials at a V/III ratio of $\sim 4000$. The target layer thickness was $50 \mathrm{~nm}$. The temperature for the pre-exposure step and for the subsequent GaP growth was the same. In Table 1, the pre-exposure conditions for each sample are summarized.

The crystalline structure of the layers was characterized using transmission electron microscopy (TEM). Samples were examined in a Philips Tecnai F20 operated at $200 \mathrm{kV}$. Samples were prepared in cross-section by standard sample preparation methods, mechanical
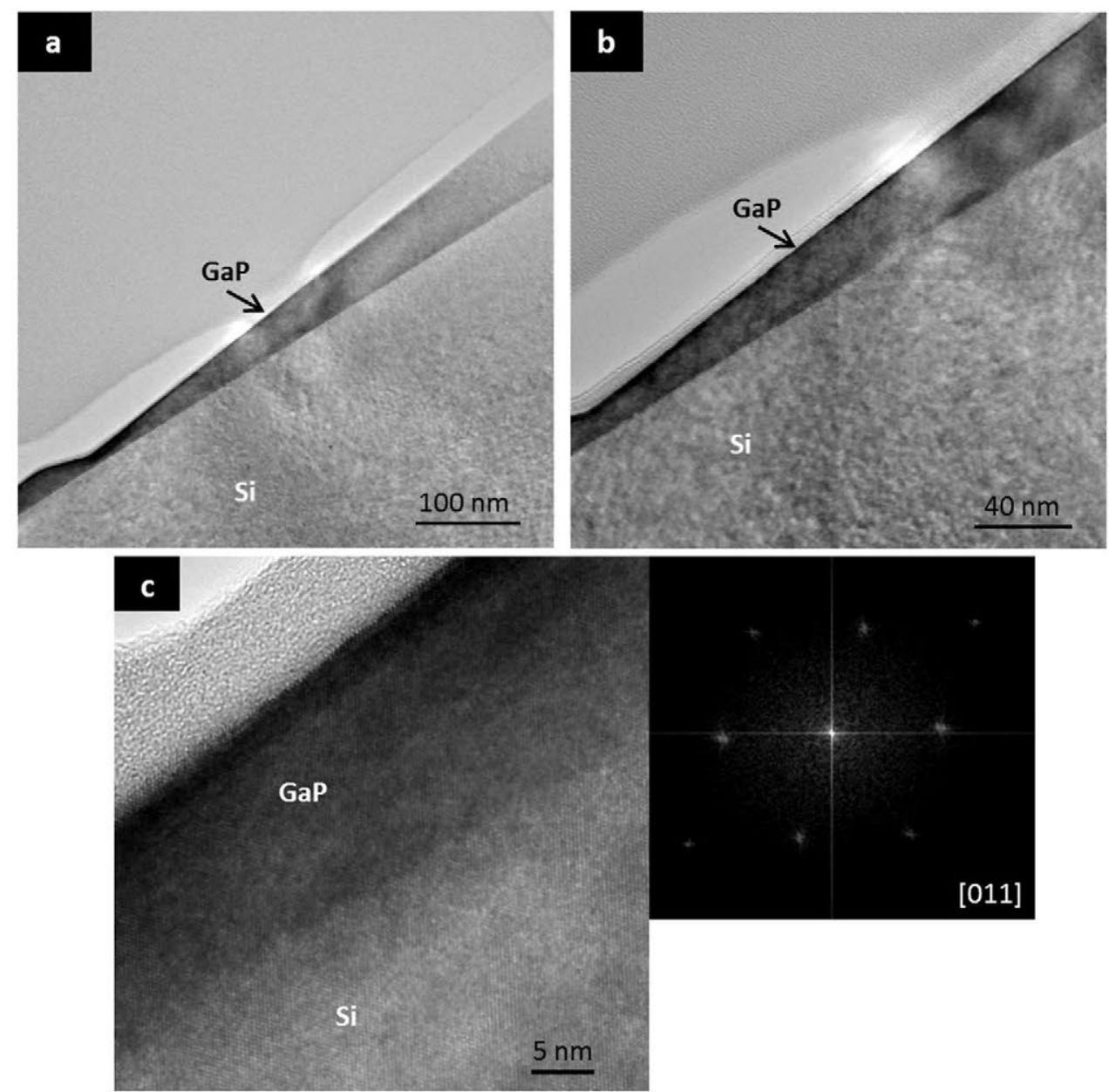

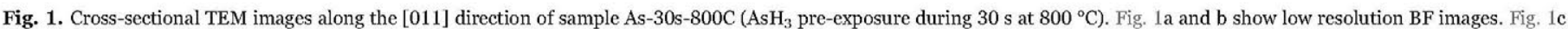
shows HRTEM and FFT analysis. 

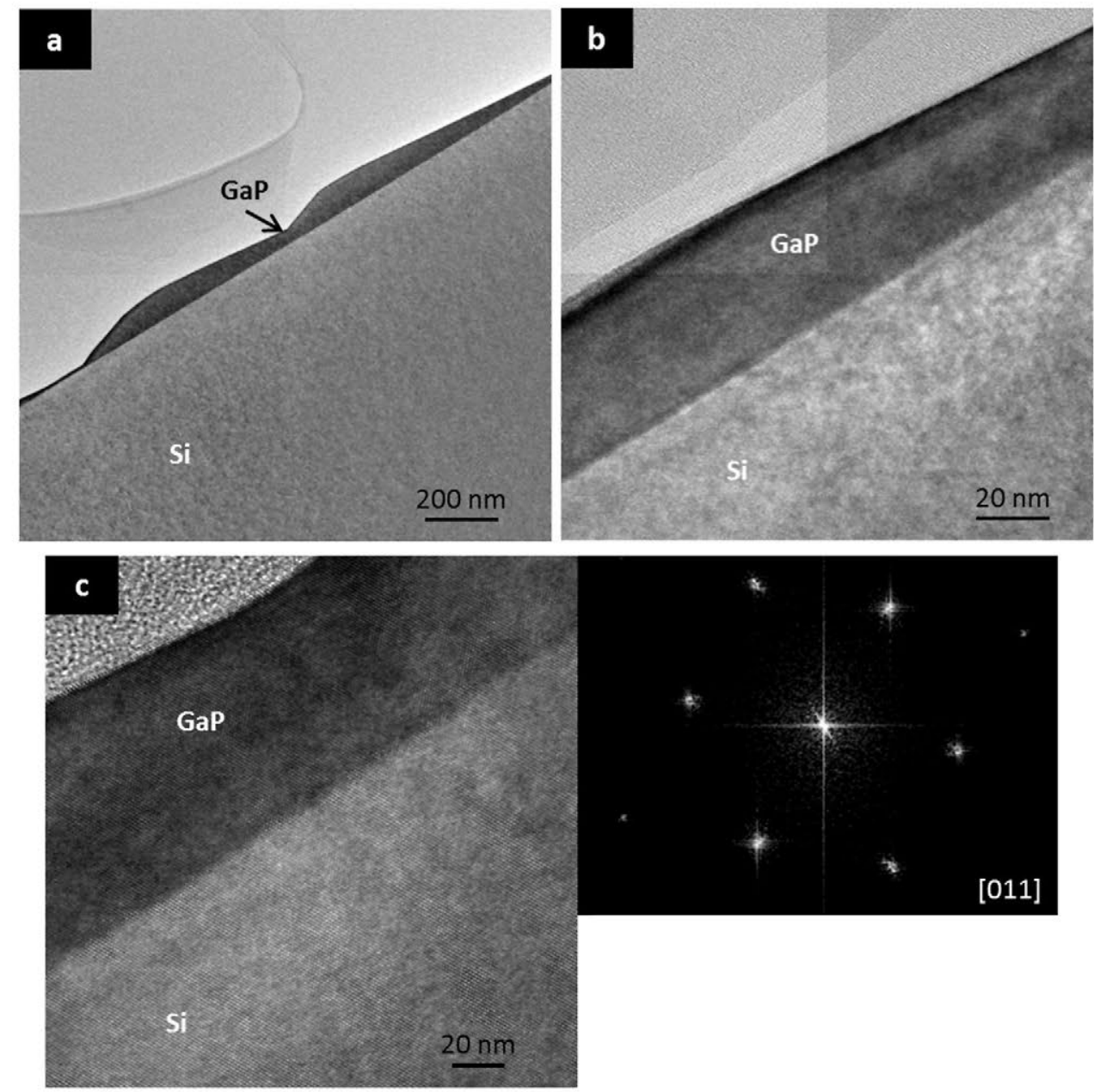

Fig. 2. Cross-sectional TEM images along the [011] direction of sample As-360s-800C $\left(\mathrm{AsH}_{3}\right.$ pre-exposure during $6 \mathrm{~min}$ at $\left.800^{\circ} \mathrm{C}\right)$. Figs. $2 \mathrm{a}$ and $2 \mathrm{~b}$ show low resolution $\mathrm{BF}$ images. Fig. 2c shows HRTEM and FFT analysis.
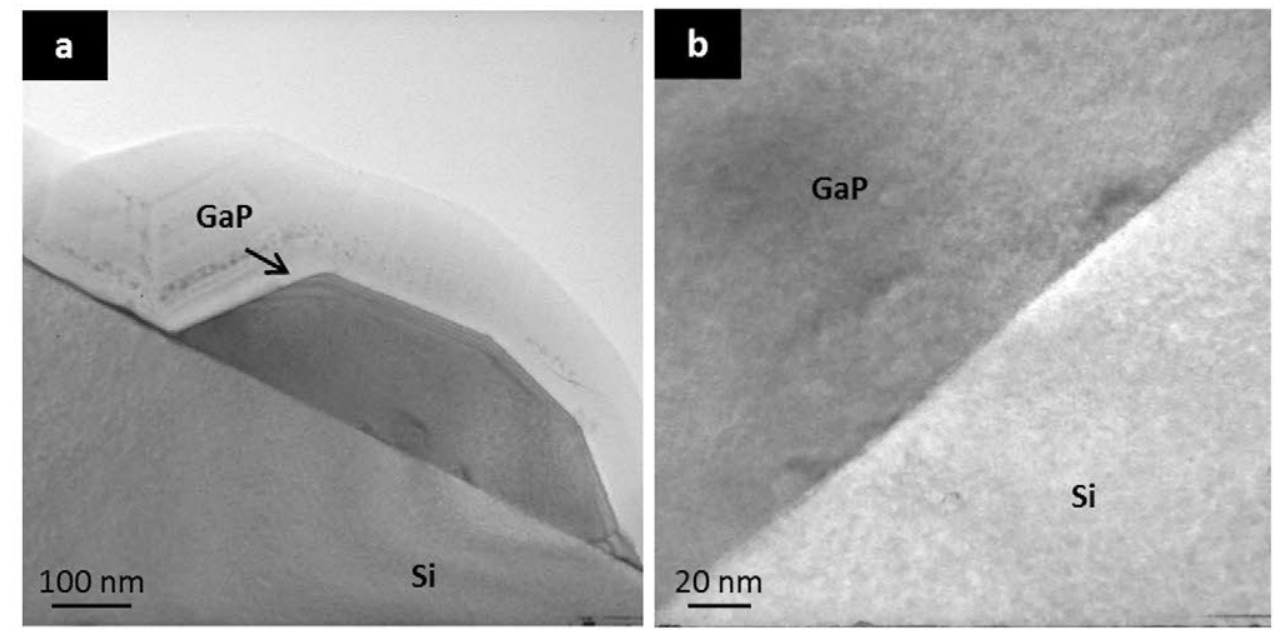

Fig. 3. Cross-sectional TEM images along the [011] direction of sample $\mathrm{P}-30 \mathrm{~s}-800 \mathrm{C}\left(\mathrm{PH}_{3}\right.$ pre-exposure during $30 \mathrm{~s}$ at $\left.800{ }^{\circ} \mathrm{C}\right)$. Fig. 3 a shows low resolution $\mathrm{BF}$ image. Fig. $3 \mathrm{~b}$ shows HRTEM analysis.

thinning and argon ion milling to electron transparency. High resolution TEM (HRTEM) images were also acquired for studying the local crystalline quality. Electron diffraction pattern and diffraction pattern simulations after fast Fourier transform (FFT) of HRTEM images were also used.

\section{Results}

In order to analyze the crystal quality of the GaP layers grown on $\mathrm{Si}$ as well as the properties of the interface, the different $\mathrm{GaP} / \mathrm{Si}$ samples described in Table 1 were characterized by TEM.

Fig. 1 gathers the cross-sectional TEM images along the [011] direction for the sample pre-exposed to $\mathrm{AsH}_{3}$ during $30 \mathrm{~s}$ at $800{ }^{\circ} \mathrm{C}$ 


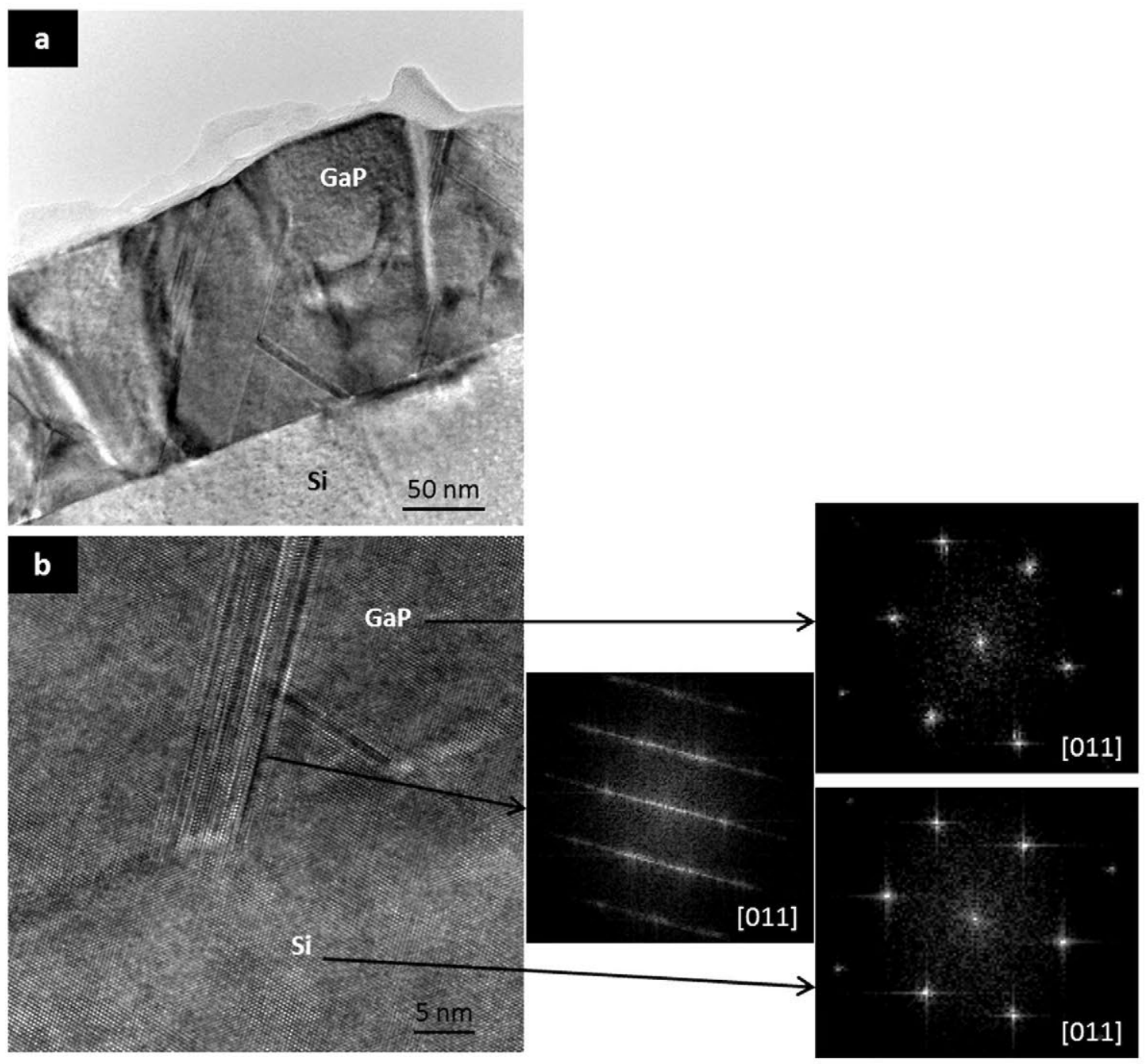

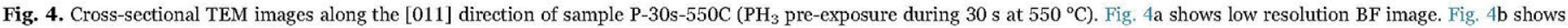
HRTEM and FFT analysis of different regions.

(sample As-30s-800C). Fig. 1a and b show low resolution bright field (BF) images of the GaP layer deposited. Both images reveal the presence of a continuous and defect-free GaP layer, without any observable threading dislocations or stacking faults, which completely covers the Si surface. Additionally dark field images, not shown, reveal no APDs, as expected by using substrates with a $2^{\circ}$ miscut toward the nearest (111) plane. Fig. 1c presents a characteristic HRTEM and the corresponding FFT analysis made in both the GaP layer and the $\mathrm{Si}$ substrate simultaneously. It shows the absence of crystallographic defects both in the interface and in the layer. The FFT analysis of the interface proves a good epitaxial growth of the GaP layer, since no rotation or double spots were observed.

In order to verify the influence of the $\mathrm{AsH}_{3}$ pre-exposure time, an additional sample grown at the same temperature with the same molar flow but using a $6 \mathrm{~min}$ of $\mathrm{AsH}_{3}$ pre-nucleation time was analyzed (sample As-360s-800C). Analogously to Fig. 1, Fig. 2 presents TEM images along the [011] direction of sample As-360s-800C. Fig. 2a shows a general view of the surface and Fig. $2 b$ presents a more detailed image. Fig. 2c presents a HTREM image and the FFT analysis made in both the GaP layer and Si substrate simultaneously.

The next step was to check if the use of $\mathrm{PH}_{3}$ at high temperature also results in a defect free $\mathrm{GaP}$ on Si. Fig. $3 \mathrm{a}-\mathrm{b}$ present cross-sectional TEM images of the sample pre-exposed to $\mathrm{PH}_{3}$ at high temperature, $800{ }^{\circ} \mathrm{C}$ (sample P-30s-800C). Fig. 3a is a low magnification image taken in BF along the [011] direction. In Fig. 3a an island-type growth of the GaP layer is clearly observable, these hillocks being interconnected by a thin $9 \mathrm{~nm}$ GaP layer. So, using $\mathrm{PH}_{3}$ pre-exposure, a nonuniform GaP layer is obtained but still the islands formed seem to be of high crystal quality with well-defined and clean interfaces as shown by Fig. 3b.

Once the pre-growth/growth at high temperature had been tested, low temperature pre-growth/growth using $\mathrm{AsH}_{3}$ as well as $\mathrm{PH}_{3}$ were studied.

Fig. 4a-b show cross-sectional TEM images along the [011] direction of the sample pre-exposed to $\mathrm{PH}_{3}$ at low temperature, $550{ }^{\circ} \mathrm{C}$ (sample P-30s-550C) and Fig. 5a-b are for the sample grown after $\mathrm{AsH}_{3}$ pre-exposure at $550{ }^{\circ} \mathrm{C}$ (sample $A s-30 s-550 \mathrm{C}$ ). Figs. $4 \mathrm{a}$ and $5 \mathrm{a}$ are low magnification images taken in $\mathrm{BF}$ along the [011] direction and Figs. $4 \mathrm{~b}$ and $5 \mathrm{~b}$ are the corresponding HRTEM images with the FFT diagrams of different regions of the HRTEM image in order to determine the crystalline structure.

The images for both samples grown at low temperature (Figs. 4 and 5) are qualitatively similar despite the different pre-exposure species used. They show a continuous but rough GaP layer, plenty of defects such as stacking faults and twins. In most cases, defects seem to originate at the $\mathrm{GaP} / \mathrm{Si}$ interface, although in some cases they start in the GaP layer. It can be observed that the nucleation layers present a high number of stacking faults along the $\{111\}$ planes. 


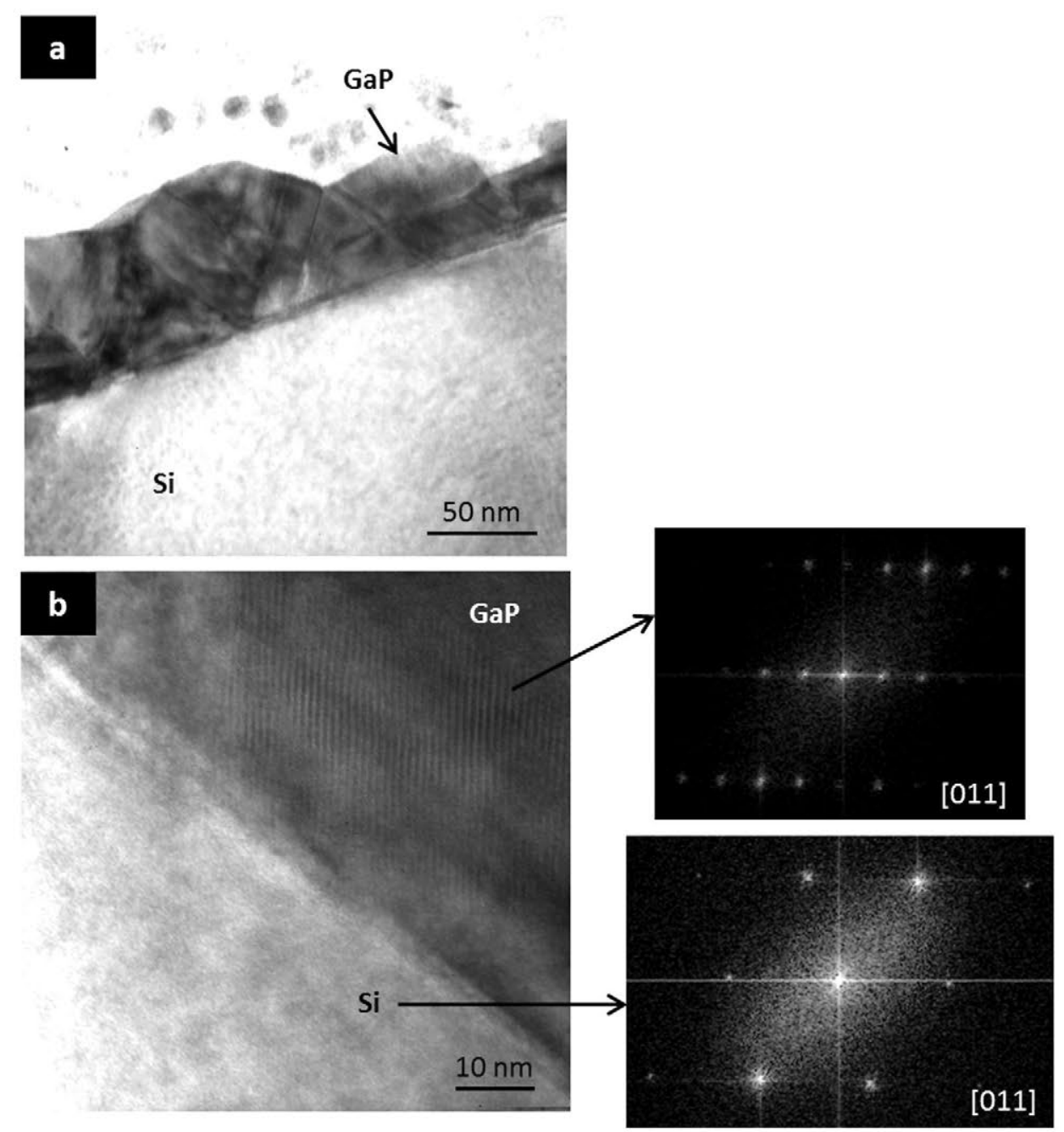

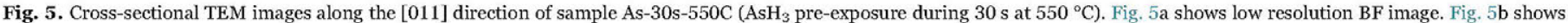
HRTEM and FFT analysis.

\section{Discussion}

Analyzing samples pre-exposed to $\mathrm{AsH}_{3}$ (Figs. 1 and 2), it can be concluded that the duration of $\mathrm{AsH}_{3}$ pre-exposure at high temperature is not critical to the crystal quality of the GaP layer and the $\mathrm{GaP} / \mathrm{Si}$ interface, at least for the one molar flow of arsine and the one preexposure temperature used for both samples, although other authors have reported an increment in roughness with $\mathrm{AsH}_{3}$ flows and times $[20,21]$.

Summarizing the data about $\mathrm{GaP}$ nucleation at high temperature in Figs. 1-3, it seems that the use of $\mathrm{AsH}_{3}$ pre-exposure leads to a continuous GaP layer without defects.

This result can be due to the combined influence of several factors: i) an effective removal of residual $\mathrm{C}$ and $\mathrm{O}$ at the $\mathrm{Si}$ surface by $\mathrm{AsH}_{3}[19]$; ii) stable $\mathrm{As}-\mathrm{Si}$ bonds (stronger than $\mathrm{P}-\mathrm{Si}$ ) which, in turn, will favor the formation of a 2D nucleation layer during the exposure of $\mathrm{Si}$ wafers to an $\mathrm{AsH}_{3}$ preflow [6]; and iii) the covalent radius of As atoms being only slightly larger than that of $\mathrm{Si}$, which makes As atoms very likely to produce a continuous and stable coverage of $\mathrm{Si}$ surfaces even at high temperatures, favoring 2D-growth. Additionally, the GaP layer grows without defects for different $\mathrm{AsH}_{3}$ exposure times. Warren et al. [18] published very good results of $\mathrm{GaP}$ on $\mathrm{Si}$ using $\mathrm{AsH}_{3}$ for slightly lower temperatures and lower $\mathrm{AsH}_{3}$ exposures, but also reported a decrease in layer quality with $\mathrm{AsH}_{3}$ exposure time. It seems that using low flows, a high quality $\mathrm{GaP} / \mathrm{Si}$ interface can be achieved even for high exposure times. This result is of relevance for the development of a low budget multijunction solar cells process, since the formation of a $\mathrm{Si}$ p-n junction by diffusion in the same growth just before the GaP layer allows decreasing the duration of the complete routine since growth interruptions or extra equipment are not required.

Regarding the sample grown with $\mathrm{PH}_{3}$ pre-exposure at high temperature (Fig. 4), the coalescence of islands is hardly obtained and a 3D-growth is commonly observed. According to previous studies, the use of low preflow times of $\mathrm{PH}_{3}$ has been shown to result in islandtype growth and a high density of V-shaped pit formation [13]. However, under certain conditions, $\mathrm{PH}_{3}$ pre-flows can produce good results, both at high and at low temperatures [13-15]. It is important to remark that in those works at high temperature $[13,14]$, the $\mathrm{Si}$ substrate was annealed above $850^{\circ} \mathrm{C}$ before nucleation, so it seems that the substrate preparation using $\mathrm{PH}_{3}$ requires higher annealing temperatures than when $\mathrm{AsH}_{3}$ is used, increasing the thermal budget of the process.

Another interesting observation is that the use of low temperature growth using $\mathrm{AsH}_{3}$ or $\mathrm{PH}_{3}$ leads to the formation of a GaP layer with a lot of defects, especially $\{111\}$ stacking faults. During three dimensional growth, the accommodation and coalescence of islands can favor the growth along the $\langle 111\rangle$ direction. When a III or V atom arrives to a $\{111\}$ plane, there are two equivalent positions in which the setting of the tetrahedral bonds characteristic of the zinc-blende structure are maintained. One of them results in the correct stacking of the atoms and the other one creates a stacking fault. If growth occurs along the < $100>$ direction, the tetrahedral coordination is maintained in any 
possible position for incorporating new atoms and the crystal structure of the substrate is also maintained. Therefore, the presence of stacking faults indicates growth following the $\langle 111\rangle$ direction, and thus it is an indirect evidence of 3D-growth followed by island coalescence.

This result is coherent with the success of $\mathrm{GaP} / \mathrm{Si}$ nucleation reported in [15], where very low temperatures $\left(\sim 450^{\circ} \mathrm{C}\right)$, specific precursors such as TBP, and pulsed growth (i.e. ALE) were needed to overcome the trend of $\mathrm{GaP}$ growing in 3D-mode at low temperature. In addition, very high $\mathrm{Si}$ annealing temperatures (above $850^{\circ} \mathrm{C}$ ) or/and $\mathrm{Si}$ homoepitaxy were needed to achieve high quality $\mathrm{GaP}$, increasing the complexity of the growth.

\section{Summary and conclusions}

We have studied the growth of GaP $50 \mathrm{~nm}$ layer on Si by MOVPE using $\mathrm{AsH}_{3}$ and $\mathrm{PH}_{3}$ pre-exposure before growth at both high $\left(800^{\circ} \mathrm{C}\right)$ and low $\left(550^{\circ} \mathrm{C}\right)$ temperatures. The characterization has been carried out by cross-sectional TEM. The results reveal that defect-free GaP on $\mathrm{Si}$ (without threading dislocations, stacking faults or other crystallographic defects) can be achieved for a wide range of $\mathrm{AsH}_{3}$ preexposure times ( $30 \mathrm{~s}$ to $6 \mathrm{~min}$ using high temperature growth $\left(800^{\circ} \mathrm{C}\right)$ with relatively low $\mathrm{Si}$ substrate annealing temperatures $\left(850^{\circ} \mathrm{C}\right)$ and without prior homoepitaxial Si growth. Conversely, low temperature processes produce layers with high numbers of defects for both $\mathrm{AsH}_{3}$ and $\mathrm{PH}_{3}$ pre-exposures. Our $\mathrm{AsH}_{3}$ pre-exposure routine at high temperature shows promising results due to the reduction in complexity compared to previous $\mathrm{GaP} / \mathrm{Si}$ routines and opens a promising strategy for future industrial transfer, being of special interest for multijunction solar cells, since it will allow growing the complete structure in one single MOVPE reactor without growth interruptions.

\section{Acknowledgments}

This work has been partially supported by Spanish Government (MINECO through projects with references TEC2014-54260-C3-2-P and TEC2015-66722-R). TEM work has been conducted at LABMET laboratory, associated with Red de Laboratorios of CAM, Spain. Amalia Navarro holds a PhD Grant from Carlos III University of Madrid (UC3M).

\section{References}

[1] T.J. Grassman, D.J. Chmielewski, S.D. Carnevale, J.A. Carlin, S.A. Ringel, IEEE J. Photovolt. 6 (2016) 326-331.

[2] Y.B. Bolkhovityanov, O.P. Pchelyakov, Open Nanosci. J. 3 (2009) 20-33.

[3] M. Wanlass, T. Coutts, J. Ward, et al22nd IEEE PV Specialists Conference, Las Vegas, NV, pp. 38-45, 1991

[4] A. Beyer, I. Németh, S. Liebich, J. Ohlmann, W. Stolz, K. Volz, J. Appl. Phys. 109 (2011) 083529

[5] T. Soga, H. Nishikawa, T. Jimbo, M. Umeno, Jpn. J. Appl. Phys. 32 (1993) $4912-4915$.

[6] Y. Kohama, Y. Kadota, Y. Ohmachi, Jpn. J. Appl. Phys. 29 (1990) 229-232.

[7] I. Németh, B. Kunert, W. Stolz, K. Volz, J. Cryst. Growth 310 (2008) 4763-4767.

[8] H. Döscher, O. Supplie, S. Brückner, T. Hannappel, A. Beyer, J. Ohlmann, K. Volz, J. Cryst. Growth 315 (2011) 16-21.

[9] H. Kroemer, J. Cryst. Growth 81 (1987) 193-204.

[10] O. Supplie, M.M. May, P. Kleinschmidt, A. Nägelein, A. Paszuk, S. Brückner, T. Hannapel, Apl. Mater. 3 (2015) 126110.

[11] Y. Kohama, K. Uchida, T. Soga, T. Jimbo, M. Umeno, Appl. Phys. Lett. 53 (1988) 862-864.

[12] E. García-Tabarés, I. García, D. Martín, I. Rey-Stolle, J. Phys. D: Appl. Phys. 46 (2013) 445104.

[13] Y. Takano, K. Morizumi, S. Watanabe, H. Masuda, T. Okamoto, K. Noda, S. Fukuda, T. Ozeki, K. Kuwahara, S. Fuke, Y. Furukawa, H. Yonezu, Jpn. J. Appl. Phys. 48 (2009) 011102.

[14] T. Soga, T. Jimbo, M. Umeno, Appl. Surf. Sci. 82/83 (1994) 64-69.

[15] K. Yamane, T. Kobayashi, Y. Furukawa, H. Okada, H. Yonezu, A. Wakahara, J. Cryst. Growth 311 (2009) 794-797.

[16] K. Volz, A. Beyer, W. Witte, J. Ohlmann, I. Németh, B. Kunert, W. Stolz, J. Cryst. Growth 315 (2011) 37-47.

[17] M. Deura, Y. Kondo, M. Takendra, S. Takagi, Y. Shimogaki, Y. Nakano, M. Sugiyama, Jpn. J. Appl. Phys. (2011) (50 04DH07).

[18] T.J. Grassman, J.A. Carlin, B. Galiana, L. -M. Yang, F. Yang, M.J. Mills, S.A. Ringel, Appl. Phys. Lett. 102 (2013) 142102.

[19] E.L. Warren, A.E. Kibbler, R.M. France, A.G. Norman, P. Stradins, W.E. McMahon, Appl. Phys. Lett. 107 (2015) 082109.

[20] T. Hannappel, W.E. MeMahon, J.M. Olson, J. Cryst. Growth 272 (2004) 24-29.

[21] W.E. McMahon, I.G. Batyrev, T. Hannappel, J.M. Olson, S.B. Zhang, Phys. Rev. B 74 (2006) 033304. 